\title{
Towards a healthy diet: from nutrition recommendations to dietary advice
}

\author{
Agneta Andersson' and Susanne Bryngelsson² \\ 'Clinical Nutrition and Metabolism, Department of Public Health and Caring Science, Uppsala University, Uppsala, \\ Sweden; ${ }^{2}$ SNF Swedish Nutrition Foundation, Lund, Sweden
}

\section{Abstract}

The scientific knowledge regarding dietary fat, carbohydrate and protein, and food for the youngest and oldest people, was presented by key scientists in the field at a symposium arranged in Uppsala on 14 December 2006. The quality of fat and carbohydrates, rather than the total amount, was emphasized. It was more difficult, however, to reach conclusions about the preferred type of dietary protein. Recent dietary recommendations, main activities and key messages to the public in the Nordic countries, and a 5 year programme to decrease salt intake in Sweden were also presented. Some practical aspects on how to implement the recommendations in the population were highlighted. In many aspects the Nordic countries join together in similar simplified advice to the population. The symposium is summarized in this report.

\section{Introduction}

W ith the aim of reviewing the evidence for the present nutrition recommendations and how these may be transformed into practical dietary advice, a symposium in honour of Professor Bengt Vessby was held in Uppsala on 14 December 2006. ${ }^{1}$ After almost 40 years of research in the field of diet and health, especially focusing on dietary fatty acids, Vessby will retire this year. Key scientists in the field of nutrition representing all the Nordic countries were invited speakers. $^{2}$ The morning session's lectures mirrored the scientific knowledge regarding dietary fat,

\footnotetext{
${ }^{1}$ Organizers: Uppsala University (Department of Public Care and Caring Sciences, Unit of Clinical Nutrition and Metabolism and Department of Medical Sciences); Uppsala Food and Nutrition Centre; Centre for Clinical Testing of Foodstuff; Swedish Society of Clinical Nutrition, SWESPEN.

${ }^{2}$ Speakers and chairs: Professor Antti Aro, National Public Health Institute, Helsinki, Finland; Professor Nils-Georg Asp, SNF Swedish Nutrition Foundation, Lund, Sweden; Professor Wulf Becker, National Food Administration, Uppsala, Sweden; Professor Åke Bruce, National Food Administration, Uppsala, Sweden; Professor Tommy Cederholm, Uppsala University, Sweden; Professor Inga-Britt Gustafsson, Örebro University, Grythyttan; Professor Kjeld Hermansen, Aarhus University Hospital, Denmark; Professor Olle Hernell, Umeå University, Sweden; Tekn dr Anita Laser-Reuterswärd, National Food Administration, Uppsala, Sweden; Professor Jan I. Pedersen, University of Oslo, Norway; Professor Gabriele Riccardi, Federico II University, Naples, Italy; Chief Nutritionist Annica Sohlström, National Food Administration, Uppsala, Sweden; Professor Inga Thorsdòttir, Landspitali-University Hospital and University of Iceland, Reykjavik, Iceland; Professor Matti Uusitupa, University of Kuopio, Finland; Professor Bengt Vessby, Uppsala University, Sweden.
}

carbohydrate and protein. Before lunch food for the youngest and the oldest people were also commented upon, and a 5 year programme to decrease the salt intake in Sweden was presented. In the afternoon the recent dietary recommendations in the Nordic countries were presented, and some practical aspects on how to implement them in the population were highlighted. The symposium is summarized in this report.

\section{Lifestyle changes: the only way to go!}

Atherosclerotic cardiovascular disorders and cancer are very important causes of disease and premature death in most countries in the world today. The symposium was officially opened by Bengt Vessby, who emphasized that the major factors determining the prevalence of these diseases at the population level are related to people's choice of lifestyle. The World Health Organization (WHO) has estimated that $80 \%$ of all cardiovascular disease, $90 \%$ of all type 2 diabetes and $30 \%$ of all cancer could be prevented by eating a healthy diet, increasing physical activity and avoiding smoking (1).

For major changes in dietary habits it is essential to agree on nutrition recommendations, after reviewing the scientific evidence behind them. The increasing knowledge about the central role of diet for public health casts the challenge to, for example, experts in nutrition, health-care professionals and the food industry to help individuals towards 
healthier eating by transforming the recommendations into simplified dietary advice expressed as foods and food patterns.

\section{Dietary fat: focus on quality}

Fatty acids are the most energy-dense nutrients in the diet. Depending on the length of the carbon chain and the number, positions and isomeric structure of the double bonds they are differently metabolized. One of the most important health effects of dietary fatty acids is associated with atherosclerosis and its risk factors. This topic was reviewed in historical perspective by Antti Aro. The cross-cultural Seven Countries Study showed a close association between the intake of saturated fatty acids (SFA) and serum cholesterol and fatal coronary heart disease (CHD) (2). In some subsequent studies within populations the associations have been less evident, but in the largest prospective cohort, the Nurses' Health Study, it was estimated that substituting $5 \%$ of the energy $(E \%)$ SFA with monounsaturated fatty acids (MUFA) and polyunsaturated fatty acids (PUFA) reduced the risk of CHD by $42 \%$ (3).

Among the saturated fatty acids those with 12-16 carbon atoms (lauric acid, myristic acid and palmitic acid) increase serum levels of total cholesterol, low-density lipoprotein (LDL)- and high-density lipoprotein (HDL)-cholesterol, while a minor decrease in or no effect on total- and LDL-cholesterol and increased levels of HDL-cholesterol are observed after intake of stearic acid $(18: 0)(4,5)$. Whereas oleic acid (cis 18:1) is neutral, its trans form (elaidic acid) increases serum levels of totaland LDL-cholesterol and decreases the levels of HDL-cholesterol at high intake. The intake of trans fatty acids (TFA) in the Nordic countries is, however, low $\left(0.5-1 E^{\%}\right)$ (6). MUFA and PUFA have rather similar effects, decreasing the levels of total- and LDL-cholesterol compared with SFA. High intake of PUFA in combination with low intake of SFA reduced the risk of $\mathrm{CHD}$ in the Finnish Mental Hospital Study (7).

The enthusiasm about PUFA was attenuated by the antioxidant hypothesis, suggesting that CHD may be prevented by increasing the intake of antioxidants and limiting the intake of easily oxidized PUFA. However, increased intake of PUFA has not affected markers of peroxidation, suggesting that the antioxidant potential of the organism is sufficient to prevent fatty acid peroxidation at reasonable intake of PUFA (8). In addition, clinical trials with antioxidant supplementation have so far failed to support the hypothesis (9).

At moderate fat intake ( $\left.<37 E^{\%} \%\right)$, the KANWU study showed that fat substitution favouring MUFA instead of SFA affects insulin resistance positively (10). However, for high-fat diets $(>37 E \%)$ this beneficial effect of MUFA was not found. A very high total fat intake also increases fat accumulation in the liver (11), which is closely correlated with features of insulin resistance.

In the Women's Health Initiative Randomized Control Trial a reduced fat intake failed to affect the risk of breast cancer, colorectal cancer and CHD (12-14). The lack of effects may, at least partly, be explained by the fact that the intervention was only partly successful and the quality of fat was not affected. The aim was to reduce the fat intake of the intervention group to $20 \mathrm{E} \%$, but after 6 years the intake was $28.8 E \%$. This was higher than aimed for, but still considerably lower than in the control group $(37 E \%)$. The fat quality was similar in both groups (about one-third SFA and two-thirds MUFA plus PUFA of the total fat intake), and also remained similar compared with the baseline for both groups.

Taken together, available studies emphasize not only the importance of total fat intake, but particularly the fat quality for risk of disease. Among the details to be further explored, Aro suggested: (i) differences in effects of lauric (12:0) and myristic acid (14:0) versus palmitic acid (16:0); (ii) differences between animal and vegetable TFA and between trans-18:1 and trans-18:2; (iii) why palmitoleic acid (16:1) in tissues is associated with risk of diabetes and cardiovascular disease; (iv) the optimal intake ratio between omega- 6 and omega- 3 fatty acids (n-6/n-3 ratio); and (v) the essentiality for adults of long-chain n-3 PUFA.

\section{Dietary carbohydrates: make the right choice!}

Gabriele Riccardi began his presentation by stating that a very high intake of fat, independent of the fat quality, will increase the risk for overweight and have negative effects on lipoproteins, especially for people with impaired fat oxidation. A balanced diet, therefore, needs to contain a substantial amount of foods high in carbohydrates. Foods high in carbohydrates are also good sources of dietary fibre and many vitamins and minerals. 
The main features of the so-called Mediterranean diet, often referred to as a model of healthy eating habits, are a moderate intake of total fat (predominantly MUFA) and a high intake of starchy foods. Although this diet has beneficial effects on lipid metabolism, the benefits of a diet high in carbohydrates may be hampered in patients with diabetes or other conditions associated with insulin resistance (metabolic syndrome) who are known to be at particular risk of CHD. However, Riccardi meant that detrimental effects of high-carbohydrate diets only occur with high glycaemic loads, while they are abolished if the diet is based mainly on fibrerich, low glycaemic index (GI) foods (e.g. 15-17). Such carbohydrate-rich foods may reduce levels of LDL-cholesterol, improve insulin action, reduce postprandial blood glucose and increase levels of HDL-cholesterol $(18,19)$. In the long term this type of diet would be expected to confer a lower risk of type 2 diabetes and metabolic syndrome. Therefore, at the population level, readily available carbohydrates present in most processed foods should be limited in the diet, while high fibre and/or low GI foods should be used without limitation.

For refined sugars it should be remembered that they provide energy but do not provide any fibre, vitamins or minerals. Furthermore, there is some evidence that sugar-sweetened drinks give low satiation and may contribute to increased energy intake and body weight (20). There are therefore good reasons to limit the intake of refined sugars.

In conclusion, similarly to dietary fat, the quality of the dietary carbohydrates may be more important than the total amount, at least at moderate intake.

\section{Dietary protein: how much?}

Considerable debate has taken place regarding the safety of a high dietary protein intake. Key issues are the rate at which the gastrointestinal tract can absorb amino acids from dietary proteins $\left(1.3-10 \mathrm{~g} \mathrm{~h}^{-1}\right)$ and the liver's capacity to deaminate proteins and produce urea for excretion of excess nitrogen. The accepted level of protein requirement of $0.8 \mathrm{~g} \mathrm{~kg}^{-1} \mathrm{day}^{-1}$ is mainly based on structural requirements and ignores the use of protein for energy metabolism. According to Kjeld Hermansen an estimated appropriate maximal protein intake based on bodily needs, weight control evidence and avoiding protein toxicity may be approximately $25 E \%\left(2-2.5 \mathrm{~g} \mathrm{~kg}^{-1}\right.$ day $^{-1}$, corresponding to $176 \mathrm{~g}$ protein per day for an $80 \mathrm{~kg}$ individual on a $12 \mathrm{MJ}$ day $^{-1}$ diet). In his lecture Hermansen also highlighted three commonly debated issues considering protein: the role of dietary proteins for (i) the risk of $\mathrm{CHD}$, (ii) weight control, and (iii) renal disease.

\section{Coronary heart disease}

Little is known about the potential impact on risk factors for CHD of high-protein diets. Results from observational studies are inconclusive considering the association between protein intake and risk of CHD. Replacing carbohydrates with proteins may be associated with a lower risk of CHD in women (21), and diets lower in carbohydrate and higher in fat and protein than usually recommended may not constitute any risk (22). However, dietary protein from animal and from vegetable food sources appears to be differently associated with mortality from CHD when substituted for carbohydrates in the diet.

Analysis of data collected from the Iowa Women's Health Study indicates that high intake of protein from red meat and dairy products is associated with an increased risk of CHD (23). The exact mechanism is not known, but the results indicate a potential risk of long-term adherence to popular high-protein diets without discriminating towards vegetable protein sources.

In 1999 the US Food and Drug Administration (FDA) approved labelling for foods containing soya protein (6.25 g serving four times a day) as protective against CHD. This decision was based on clinical studies showing that at least $25 \mathrm{~g}$ of soya protein per day lowered total cholesterol and LDLcholesterol (24). However, a recent meta-analysis of 22 clinical trials performed during the past 10 years did not show any clinically important favourable effect of soya protein on LDL-cholesterol (25). A very large amount of soya protein (more than half of daily protein intake) may lower LDL-cholesterol just a few per cent when it replaces dairy or meat protein or other animal protein. Soya products may, however, be beneficial to cardiovascular and overall health owing to their high contents of PUFA, fibre and vitamins, and low content of SFA, rather than to the effects of soya proteins.

\section{Body weight management}

The advice to consume diets high in protein for weight management is provided by some health professionals, media and popular books. Intervention studies indicate that higher protein diets increase short-term weight loss among obese and 
overweight subjects, but long-term data ( $>1$ year) are so far scarce $(26,27)$. The short-term effect has been attributed to the greater satiety and thermogenic effect of protein than of carbohydrates.

\section{Renal disease and diabetes}

Recently, new nutrition guidelines specifically targeting people with type 2 diabetes were presented by the Joslin Diabetes Center, Massachusetts, USA (28). The new guidelines suggest a higher protein intake $(20-30 E \%)$ compared with the Nordic Nutrition Recommendations (NNR) (10-20E\%), but within the range recommended by official US recommendation for adults $(10-35 E \%)$. The new guidelines, however, make an exception to this recommendation for people with renal disease. A recent study also supports a nutritional intervention towards a reduction in protein intake for patients with chronic renal failure. It has been shown that reducing protein intake to $0.6 \mathrm{~g} \mathrm{~kg}^{-1}$ day $^{-1}$ in nondiabetic patients with chronic kidney disease reduces renal death by $31 \%$ (29).

According to the Diabetes and Nutrition Study Group of the European Association for the Study of Diabetes 2004 (30), convincing evidence (grade A) exists for recommendations to reduce protein in type 1 diabetes with nephropathy. For these patients the protein intake should be at the lower end of the recommended range. For patients with no evidence of nephropathy protein intake may provide $10-20 E \%$. Owing to poor studies (small groups, short duration, poor compliance) there is so far insufficient evidence to make firm recommendations regarding protein restriction in patients with type 1 diabetes and incipient nephropathy and those with type 2 diabetes and established or incipient nephropathy. There is also insufficient evidence to make recommendations about the preferred type of dietary protein.

More research is required to establish effects of high-protein diets on renal function in the absence of albuminuria, and to confirm or refute the extent to which red meat and processed meat contribute to the development of nephropathy.

\section{Salt and hypertension: a 5 year programme to decrease salt intake in Sweden}

NNR (31) and the Swedish Nutrition Recommendations (32) recommend a maximum salt intake of $6 \mathrm{~g} \mathrm{NaCl}$ day $^{-1}$ for women and $7 \mathrm{~g}$ day $^{-1}$ for men. A further reduction to $5 \mathrm{~g} \mathrm{day}^{-1}$ will have additional benefits. Some recent nutrition surveys have shown that for most individuals the present salt intake is $8-12 \mathrm{~g} \mathrm{day}^{-1}$ (33). The major sources are meat and mixed meat products $(33 \%)$, cereal products (excluding bread) (13\%), bread (11\%), fish $(7 \%)$, potatoes and other vegetables $(11 \%)$, cheese $(5 \%)$, and butter and margarine (4\%).

Ake Bruce presented a national salt reduction programme, planned by the Swedish National Food Administration, aiming at a $50 \%$ reduction in the present salt intake, to $5-6 \mathrm{~g} \mathrm{day}^{-1}$ by a gradual decrease, with approximately $0.5 \mathrm{~g}$ semi-annually for the coming 5 years. Salt reduction programmes in Finland and the UK are important models.

The Swedish programme will start in 2007 and will be carried out in close collaboration with the Swedish Food Federation $(\boldsymbol{L} \boldsymbol{i})$, the Federation of Swedish Hotels and Restaurants (SHR) and the Swedish Food Retailers Federation. A decrease in the individual preferences for saltiness as well as a decrease in sodium content regardless of saltiness (e.g. by the use of mineral salt) will be considered.

\section{Food and the youngest}

Because of the rapid growth rate, energy and nutrient requirements in infancy and early childhood are higher than later in life. This is reflected by current recommendations of more energy- and nutrient-dense food during the first 2 years of life. At the same time, margins of safety with respect to deviation from optimal nutrient composition of the food are narrower owing to physiological and metabolic functions not being fully developed. For instance, some nutrients, e.g. long-chain PUFAs, may be conditionally essential in early life, while other nutrients, e.g. iron, may have adverse effects when given in excess to iron-replete infants. Olle Hernell commented on some important issues related to food for the youngest, including breastfeeding in relation to coeliac disease, iron and omega-3 fatty acids.

\section{Breast-feeding and development of coeliac disease} The composition of human milk has for long been regarded as the reference for the composition of infant formulae, and there is evidence for short- and long-term health benefits of breast-feeding. On a population level NNR recommends exclusive breast-feeding for 6 months, with no other foods except for vitamin D supplements (NNR 2004). It has been questioned whether this is the optimal 
recommendation to reduce the risk of developing coeliac disease. It is known that breast-feeding during the gradual introduction of gluten is protective, and there are indications that it may be beneficial to introduce gluten within the interval of 4-6 months of age (34). However, most studies refute that the infant's age at the time of gluten introduction is an independent risk factor for coeliac disease, and this question needs to be further explored.

\section{Early feeding and iron intake}

The iron content is as low in human milk as in cow's milk and breast-feeding does not meet the recommended intake of $8 \mathrm{mg}$ day $^{-1}$. To avoid iron deficiency it is important to start complementary feeding no later than at 6 months of age. The complementary food should be rich in iron, and cow's milk should therefore be avoided before the age of 1 year. Giving excess iron to iron-replete infants should be avoided, since this may adversely affect linear growth $(35,36)$.

\section{Omega-3 fatty acids}

In spite of their increased capacity to synthesize long-chain PUFA, preterm formula-fed infants need preformed docosahexanoic acid (DHA) and arachidonic acid (AA) for optimal neurodevelopment (37). There are indications that those fatty acids may also be beneficial for term infants, but there is a lack of scientific consensus and NNR does not include any recommendations on long-chain PUFA.

\section{Early nutrition and future health}

It is recognized that breast-feeding may provide protection form infections and some immunemediated diseases such as type 1 diabetes and coeliac disease even after breast-feeding has been discontinued (38). For example, preterm infants breast-fed during the first 4 weeks had a better risk profile (higher insulin sensitivity, improved endothelial function, lower blood pressure and lower serum cholesterol) at the age of 13-16 years than formula-fed infants (39). The effects were not great, and may not be important on an individual level, but beneficial on a population level. In fact, early infant feeding in general, and perhaps breastfeeding in particular, may affect neurodevelopment and have imprinting effects on metabolic functions lasting into adulthood, impacting on risk factors for diseases such as obesity, elevated blood pressure, insulin resistance and type 2 diabetes. One imprinting mechanism may be epigenetics, i.e. the expression of a gene or certain genes may be permanently changed by certain nutrients, or composition of the diet, either to the mother during pregnancy or to the infant during early postnatal life (40). Thus, early metabolic imprinting may be of great importance for health and disease in adult life.

\section{Food for the oldest}

It is most likely that a previous healthy lifestyle combined with genetic disposition has permitted the individual to become aged, and as long as health and vigour prevail there is usually no need for the elderly individual to change their dietary habits. However, reduced appetite, loss of smell and taste, chewing and swallowing problems, and reduced physical activity are typical features of the ageing process. Moreover, metabolic alterations such as insulin resistance, less active inflammation, increased oxidation processes, reduced generation of growth and sex hormones, and muscle mass remodelling need to be considered in dietary and lifestyle recommendation to the oldest people. Tommy Cederholm summarized dietary changes that may be beneficial for elderly subjects becoming frail owing to degenerative processes to combat unintentional weight loss, reduced muscle strength and a fragile skeleton.

Evidence is strong that weight loss in the elderly is deleterious, and an increased fat content, up to $40-50 E \%$, is recommended to weight-losing elderly people to allow a sufficiently energy-dense diet. It may be beneficial to increase mainly oleic acid and omega-3 fatty acids from fish (41), even though the cardiovascular risk is usually low in the very old, and scientific evidence on the exact fat quality that should be recommended is lacking. For muscle integrity an increased protein intake up to $1.0-1.5 \mathrm{~g} \mathrm{~kg}^{-1} \mathrm{day}^{-1}$ is likely to be beneficial (42). Calcium intake usually needs to be supplemented and vitamin D needs to be provided. Food supplementation can augment, but never replace the importance of physical activity for muscle strength and cardiorespiratory fitness (43). Vitamin and mineral supplementation, as well as antioxidant-rich foods, are likely to be beneficial to "small-eating" elderly people, although the evidence is sparse. The oldest fully authenticated human in the world ever documented lived to 122 years. This woman, Jeanne Louise Calment (1875-1997), attributed her happy long life to "survival" genes (her 
parents lived to 94 and 86 years), an active life (she still rode a bicycle at the age of 100) and a diet including olive oil, port wine and chocolate.

\section{Nordic Nutrition Recommendations and dietary habits}

The NNR outline the average nutrient composition of the desired diet for the Nordic populations (31). They are aimed primarily at planning diets for different groups of people. Wulf Becker summarized the 4th edition of the NNR, published in 2004, and gave an overview of the consumption of some food categories.

\section{Evidence-based recommendations}

A popular view in media is that the dietary recommendations frequently change, and that there is disagreement among experts about desirable changes. Various "new diets" are frequently launched claiming to be the healthy alternative, often in considerable contrast to present dietary recommendations. In general, however, the existing evidence favours the present recommendations and the evidence base supporting the recommendations has been successively strengthened during recent years. Several studies on dietary patterns in line with NNR have shown positive effects on health, e.g. lower blood pressure, reduced risk of coronary death, favourable blood lipids and reduced risk of type 2 diabetes. In addition, observational and intervention studies have shown a reduced risk of weight gain and some cancers.

\section{News in NNR 2004}

The updated NNR are in line with several other national and international recommendations and are mainly unchanged from the previous version regarding the proportion of energy-providing nutrients. One of the most important new features in the 4 th edition is the integration of nutritional recommendations with recommendations regarding physical activity (Box 1). In addition, the recommended intake of vitamin $\mathrm{D}$ and $\mathrm{C}$, and for women also folate, is increased. It is also the first time that NNR have included general food-based dietary guidelines and a chapter on eating patterns.

\section{Dietary habits}

Regarding dietary patterns, both positive and negative trends are observed from national food balance sheets and food consumption surveys in the
Nordic countries. The major future challenges regarding dietary changes are: (i) to increase the intake of fruit and vegetables, wholegrain cereals and fish; (ii) to shift to soft fats, and lean diary and meat products; and (iii) to decrease the consumption of sugar-rich foods.

\section{The keyhole: a healthy choice}

Many studies show that it is difficult for many consumers to understand and use nutrition labelling for foodstuffs. People are not eating nutrients but foods, and choosing foods not only for nutritional reasons. After this introduction, Anita Laser Reuterswärd, Swedish National Food Administration (NFA), presented facts about the keyhole symbol. The symbol is a voluntary labelling system, based on the nutrient claims "low in fat, sugars, salt, and/or high in fibre" (www.nyckelhalet.se). The symbol is a positive label, helping the consumer to make healthier choices. In 2005, a quick answer test was performed on around 500 consumers. Around $90 \%(52 \%$ and $38 \%)$ of the consumers answered that they "know about and/or understand" and "know about and understand fairly well" the symbol, respectively.

The keyhole symbol was introduced by NFA in 1989 , and is also a trademark. After the revision of the rules 2005 (44), there are 26 food categories with conditions set by category: dairy, fish and meat products; vegetable alternatives; low-fat spreads; fruit, vegetables and potatoes; cereals and some groups of ready meals. Previously, ice-cream and whey products were included, but when the criteria were revised in 2005, these foods were consider to be too sweet and were excluded. Oils, containing 100\% fat, are not eligible, since a main keyhole message is low fat content.

In an ordinary, quite large shop one can find around 900 products carrying the symbol. However, up to around 2000 products would fulfil the criteria and could be labelled with the symbol. The keyhole labelling is meant as an incitement for product development, and the Swedish food industry is very interested in using the symbol on prepackaged foodstuffs.

\section{Dietary advice: current status in the Nordic countries}

The current status in the different Nordic countries, considering the selection of dietary advice presented to the population and how such advice is 
Box 1. Main news in NNR (4th edn) (31)

Recommendations about physical activity

Adults: At least 30 min moderate activity per day, corresponding to about $639 \mathrm{~kJ}$ (150 kcal) "extra"

per day. For weight gain prevention, 60 min per day may be needed.

Children: At least 60 min moderate/intensive activity per day.

New chapter: Food-based dietary guidelines

Expanded chapters: Eating pattern, Dietary antioxidants, Breast-feeding

Recommended intake (RI) (per day)

Vitamin A (women)

Vitamin C (adults)

Vitamin D (2-60 years)

Folate (women $18-30$ years)

(pregnant and lactating)

Copper

$\begin{array}{lr}\text { NNR 2004 } & \text { NNR 199 } \\ 700 \mathrm{RE} & 800 \mathrm{RE} \\ 75 \mathrm{mg} & 60 \mathrm{mg} \\ 7.5 \mu \mathrm{g} & 5 \mu \mathrm{g} \\ 400 \mu \mathrm{g} & 300 \mu \mathrm{g} \\ 500 \mu \mathrm{g} & 400 \mu \mathrm{g} \\ 0.9 \mathrm{mg} & \end{array}$

communicated, was commented on by Matti Uusitupa, Finland, Kjeld Hermansen, Denmark, Jan I. Pedersen, Norway, Inga Thorsdottir, Iceland, and Annica Sohlström, Sweden. The presentations were followed by an open discussion regarding "how to proceed?" chaired by Nils-Georg Asp. From this session it was evident that the dietary key advice is almost identical in all the Nordic countries, and in many aspects the countries join together in similar simplified advice to the population. The basic advice has also been more or less constant for a long time, but today is expressed more specifically by highlighting frequency of intake and specific foods or classification of dietary sources.

In Finland, a heart symbol aiming to help the consumer to make better choices mainly regarding the quality and quantity of fat and the quantity of sodium has been used since 2000 (www.sydanme rkki.fi), and in 2005 an action plan with guidelines for the promotion of the Finnish heart health was published (www.sydanlitto.fi/en_GB).

As in Finland (see below), mortality from myocardial infarction (MI) has declined in Norway since the early 1970s. Predictive equations for serum cholesterol and fat intake, as well as what is known from prospective studies about the risk of serum cholesterol, indicate that dietary changes including fat quality and replacing boiled coffee with filtered coffee have contributed to this decline in MI. The preventive work, including giving dietary information to the population in combination with activities aimed at the food industry (e.g. the margarine industry) can therefore be regarded as reasonably successful.

Several public health nutrition action plans, many of them focusing on children, are ongoing in Iceland. The plans are administered by official health authorities, researchers and private companies. A project organized by the Public Health Institute, "Everything affects us, especially ourselves", has the goal of promoting a healthy lifestyle in children and their families (www.lydheilsustod.is). A project organized by the Unit for Nutrition Research, "Nutrition of schoolchildren - determinants of healthy food habits", is part of a lifestyle intervention in 7-9-year-old children, and aims to promote healthy food habits.

The dietary advice communicated to the population in Sweden and Denmark is in good agreement (Box 2). However, in contrast to Sweden, the use of symbols on food packages has so far not been successful in Denmark.

Sohlström emphasized the 79 points presented by the National Food Administration and the National Institute of Public Health in 2005, as background material to a national plan for healthy dietary habits and increased physical activity in Sweden (45). Various actors have implemented some measures, but so far no action plan has been adopted by the 
Box 2. Swedish and Danish dietary advice to the population

Sweden: National Food Administration (www.slv.se)

1. Eat plenty of fruit and vegetables - preferably $500 \mathrm{~g}$ a day!

2. Eat bread with all meals - preferably whole grain!

3. Choose preferably keyhole-labelled foods!

4. Eat fish - preferably three times a week!

5. Change to fluid margarines and oils when cooking!

Denmark: Fitness and Nutrition Council (www.meraadet.dk)

1. Eat fruit and vegetables - six pieces per day

2. Eat fish and fish products - several times a week

3. Eat potatoes, rice, pasta and wholemeal bread - every day

4. Limit intake of sugar - particularly from soft drinks, confectionery and cakes

5. Eat less fat - particularly fats from meat and dairy products

6. Eat a varied diet - and maintain a healthy body weight

7. Drink water when you are thirsty

8. Engage in physical activity - at least 30 min per day

Swedish government. Political leadership at the highest level is needed!

\section{What can be achieved? The Finnish success}

With recent statistics showing that the leading causes of deaths in the world are related to lifestyle, such as nutrition, smoking, alcohol and physical activity, the question "what can be achieved?" is highly relevant. This question was answered by Matti Uusitupa with several examples from Finland, which in many ways is a forerunner when it comes to lifestyle changes and positive health effects. In Finland there has been a marked decline in cardiovascular mortality in the past 30 years. In both men and women, the age-adjusted mortality from CHD has been reduced by at least $75 \%$. This is related to changes in lifestyle: smoking cessation in men, a remarkable reduction in the intake of total and saturated fats, and an increased consumption of fruit and vegetables. The mean salt intake has also been reduced. The reduction in CHD mortality can largely be attributed to the changes in serum cholesterol and blood pressure levels.

The recent follow-up study based on the Finnish Diabetes Prevention Studies showed that lifestyle changes including weight reduction, increased physical activity and dietary changes seem to have permanent effects on the reduction in the risk of diabetes. In Finland this work is ongoing and a nationwide programme aiming to prevent diabetes has been established.
In Finland a lot has been achieved by lifestyle changes, and Uusitupa summarized some key points that are important for successful work in this field in the future: (i) solid evidence is needed and available behind nutritional recommendations; (ii) the commitment of health professionals is necessary; (iii) the attitude to dietary approaches could be changed; (iv) the commitment of policy makers is needed; (v) the role of the food industry and restaurants is important; and (vi) the individual has a responsibility.

\section{The meal and culinary arts in healthy eating}

As the final speaker, Inga-Britt Gustafsson highlighted that the diet is more than nutrients and individual foods. Changing dietary habits is a complex process, and dietary recommendations without consideration of the individual's preference and behaviours will probably not be successful in the long run. Food preference is built on traditions, culture and exposure to a variety of food and meals during a person's lifetime. The meal should be considered in a wider perspective with "conscious cooking". This perspective could be defined as the "eating sphere", including the room, the people, the products, and the logistics and cost related to the meal. These four aspects will create an atmosphere, completing the Five Aspects Meal Model (FAMM) (46). Eating a meal in a pleasant environment may be one factor needed for successful lifestyle changes. Acceptability ratings of identical food is dependent 
on the situation/location were the meal is served (47). Another direction may be to train people's preferences. The SAPERE method, which trains young people to improve their sensory functions and discrimination, is one example of this. A large-scale intervention study with this method is running in France ("Ensemble, prévenons l'obésié des enfants"). The SAPERE method has also been practised in some Swedish schools, but the long-term effects would also need to be explored in the Nordic countries.

\section{References}

1. Anon. WHO Technical Report Series 916: Diet, nutrition and the prevention of chronic diseases. Report of a joint FAO/WHO Expert Consultation. Geneva: World Health Organization; 2003.

2. Keys A, Mienotti A, Karvonen MJ, Aravanis C, Blackburn $\mathrm{H}$, Buzina R, et al. The diet and 15-year death rate in the Seven Countries Study. Am J Epidemiol 1986; 124: $903-15$.

3. Hu FB, Stampfer MJ, Manson JE, Rimm E, Coditz GA, Rosner BA, et al. Dietary fat intake and the risk of coronary heart disease in women. N Engl J Med 1997; 337: 1491-9.

4. Zock PL, de Vries JH, Katan MB. Impact of myristic acid versus palmitic acid on serum lipid and lipoprotein levels in healthy women and men. Arterioscler Thromb 1994; 14: 567-75.

5. Kris-Etherton PM, Yu S. Individual fatty acid effects on plasma lipids and lipoproteins: human studies. Am J Clin Nutr 1997; 65: 1628-44S.

6. Aro A, Becker W, Pedersen JI. Trans fatty acids in the Nordic countries. Scand J Food Nutr 2006; 50: 151-4.

7. Turpeinen $\mathrm{O}$, Karvonen MJ, Pekkarinen M, Miettinen M, Elosuo R, Paavilainen E. Dietary prevention of coronary heart disease: the Finnish mental hospital study. Int J Epidemiol 1979; 8: 99-118.

8. Freese R, Alfthan G, Jauhiainen M, Basu S, Erlund I, Salminen I, et al. High intakes of vegetables, berries, and apples combined with a high intake of linoleic or oleic acid only slightly affect markers of lipid peroxidation and lipoprotein metabolism in healthy subjects. Am J Clin Nutr 2002; 76: 950-60.

9. Bleys J, Miller ER III, Pastor-Barriuso R, Appel LJ, Guallar E. Vitamin-mineral supplementation and the progression of atherosclerosis: a meta-analysis of randomized controlled trials. Am J Clin Nutr 2006; 84: $880-7$.

10. Vessby B, Uusitupa M, Hermansen M, Riccardi G, Rivellese AA, Tapsell LC, et al. Substituting dietary saturated for monounsaturated fat impairs insulin sensitivity in healthy men and women: the KANWU Study. Diabetologia 2001; 4: 312-9.

11. Westerbacka J, Lammi K, Häkkinen AM, Rissanen A, Salminen I, Aro A, Yki-Järvinen H. Dietary fat content modifies liver fat in overweight nondiabetic subject. J Clin Endocrinol Metab 2005; 90: 2804-9.

12. Beresford SA, Johnson KC, Ritenbaugh C, Lasser NL, Steselaar LG, Black HR, et al. Low-fat dietary pattern and risk of colorectal cancer: the Women's Health Initiative Randomized Controlled Dietary Modification Trial. JAMA 2006; 295: 643-54.

13. Howard BV, Van Horn L, Hsia J, Manson JE, Stefanick ML, Wassertheil-Smoller S, et al. Low-fat dietary pattern and risk of cardiovascular disease: the Women's Health Initiative Randomized Controlled Dietary Modification Trial. JAMA 2006; 295: 655-66.

14. Prentice RL, Caan B, Chlebowski RT, Patterson R, Kuller LH, Ockene JK, et al. Low-fat dietary pattern and risk of invasive breast cancer: the Women's Health Initiative Randomized Controlled Dietary Modification Trial. JAMA 2006; 295: 629-42.

15. Jenkins DJ, Kendall CW, Augustin LS, Vuksan V. Highcomplex carbohydrate or lente carbohydrate food? Am J Med 2002; 113 Suppl 9B: 30-7S.

16. Salmeron J, Manson JE, Stampfer MJ, Colditz GA, Wing AL, Willett WC. Dietary fiber, glycemic load, and risk of non-insulin-dependent diabetes mellitus in women. JAMA 1997; 277: 472-7.

17. Schulze MB, Liu S, Rimm EB, Manson JAE, Willett WC, Hu FB. Glycemic index, glycemic load, and dietary fiber intake and incidence of type 2 diabetes in younger and middle-aged women. Am J Clin Nutr 2004; 80: $348-$ 56.

18. Rivellese AA, Auletta P, Marotta G, Saldalamacchia G, Giacco A, Mastrilli V, et al. Long term metabolic effects of two dietary methods of treating hyperlipidaemia. BMJ 1994; 308: 227-31.

19. Ludwig DS. The glycemic index: physiological mechanisms relating to obesity, diabetes, and cardiovascular disease. JAMA 2002; 287: 2414-23.

20. Pereira MA. The possible role of sugar-sweetened beverages in obesity etiology: a review of the evidence. Int J Obes (Lond) 2006; 30 Suppl 3: S28-36.

21. Hu FB, Stampfer MJ, Manson JE, Rimm E, Colditz GA, Speixer FE, et al. Dietary protein and risk of ischaemic heart disease in women. Am J Clin Nutr 1999; 70: $221-7$.

22. Halton TL, Willett WC, Liu S, Manson JAE, Albert CM, Rexrode K, Hu FB. Low-Carbohydrate-diet score and the risk of coronary heart disease in women. $\mathrm{N}$ Engl Med 2006; 355: 1991-2002.

23. Kelemen LE, Kushi LH, Jacobs DR Jr, Cerhan JR. Associations of dietary protein with disease and mortality in a prospective study of postmenopausal women. Am J Epidemiol 2005:161:239-49.

24. Anderson JW, Johnstone BM, Cook-Newell ME. Metaanalysis of the effects of soy protein intake on serum lipids. N Engl J Med 1995; 333: 276-82.

25. Sacks FM, Lichtenstein A, Van Horn L, Harris W, KrisEtherton P, Winston M. Soy protein, isoflavones, and cardiovascular health. An American Heart Association science advisory for professionals from the nutrition committee. Circulation 2006; 113: 1034-44. 
26. Krieger JW, Sitren HS, Daniels MJ, Langkamp-Henken B. Effects of variation in protein and carbohydrate intake on body mass and composition during energy restriction: a meta-regression. Am J Clin Nutr 2006; 83: 260-74.

27. Due A, Toubro S, Skov AR, Astrup A. Effect of normalfat diets, either medium or high in protein, on body weight in overweight subjects: a randomised 1-year trial. Int J Obes Relat Metab Disord 2004; 28: 1283-90.

28. Anon. Joslin Diabetes Center \& Joslin Clinic clinical nutrition guideline for overweight and obese adults with type 2 diabetes, prediabetes or those at high risk for developing type 2 diabetes. Boston, MA: Joslin Diabetes Center; 30 September 2005. http://www.joslin.org/Files/ Nutrition_ClinGuide.pdf

29. Fouque D, Laville M, Boissel JP. Low protein diets for chronic kidney disease in non-diabetic adults. Cochrane Database Syst Rev 2006;CD001892.

30. Mann JI, De Leeuw I, Hermansen K, Karamanos B, Karlstrom B, Katsilambros N, et al. Diabetes and Nutrition Study Group (DNSG) of the European Association. Evidence-based nutritional approaches to the treatment and prevention of diabetes mellitus. Nutr Metab Cardiovasc Dis 2004; 14: 373-94.

31. Anon. Nutrition recommendations 2004 (4th edn). Integrating nutrition and physical activity. Nord 2004:3. Copenhagen: Nordic Council of Ministers; 2004. http:// www.norden.org/pub/sk/showpub.asp?pubnr $=2004: 013$

32. Anon. Svenska Näringsrekommendationer. Uppsala: Livsmedelsverket; 2005.

33. Brugård Konde $\AA$. Halverat saltintag räddar liv. Vår Föda 2003; 55(3): 30-2.

34. Ivarsson A, Hernell O, Stenlund H, Persson LA. Breastfeeding protects against celiac disease. Am J Clin Nutr 2002; 75: 914-21.

35. Dewey KG, Dollelöf M, Cohen RJ, Landa Rivera L, Hernell O, Lönnerdal B. Iron supplementation affects growth and morbidity of breast-fed infants: results of a randomized trial in Sweden and Honduras. J Nutr 2002; 132: $3249-55$.

36. Domellöf M, Lind T, Lönnerdal B, Persson LA, Dewey $\mathrm{KG}$, Hernell O. Effects of the mode of oral iron administration on serum ferritin and haemoglobin in infants. Manuscript.

37. Koletzko B, Agostoni C, Carlson SE, Clandinin T, Hornstra G, Neuringer M, et al. Long chain polyunsaturated fatty acids (LC-PUFA) and perinatal development. Acta Paediatr 2001; 90: 460-4.
38. Schack-Nielsen L, Michaelsen KF. Breast feeding and future health. Curr Opin Clin Nutr Metab Care 2006; 9: 289-96.

39. Singhal A, Cole TJ, Lucas A. Early nutrition in preterm infants and later blood pressure: two cohorts after randomised trials. Lancet 2001; 357: 413-9.

40. Waterland RA, Garza RC. Potential mechanisms of metabolic imprinting that lead to chronic disease. Am J Clin Nutr 1999; 69: 179-97.

41. Freund-Levi Y, Eriksdotter-Jonhagen M, Cederholm T, Basun H, Faxen-Irving G, Garlind A, et al. Omega-3 fatty acid treatment in 174 patients with mild to moderate Alzheimer disease: OmegAD study: a doubleblind trial. Arch Neurol 2006; 63: 1402-8.

42. Campbell WW, Trappe TA, Wolfe RR, Evans WJ. The recommended dietary allowance for protein may not be adequate for older people to maintain skeletal muscle. $\mathbf{J}$ Gereont A Biol Sci Med Sci 2001; 56: M373-80.

43. Fiatarone MA, O'Niell EF, Ryan ND, Clements KM, Solares GR, Nelson ME, et al. Exercise training and nutritional supplementation for physical frailty in very elderly people. N Engl J Med 1994; 330: 1769-75.

44. Anon. National Food Administration's regulations on the use of a particular symbol. LIVSFS 2005:9.

45. Anon. Background material to the action plan for healthy dietary habits and increased physical activity. National Food Administration and National Institute of Public Health; 2005. http://www.slv.se/upload/dokument/In_English/Food_and_health/TheSwedishActionplan.pdf

46. Gustafsson I-B, Öström ̊, Johansson J, Mossberg L. The Five Aspects Meal Model; a tool for developing meal services. Journal of Foodservice 2006; 17: 84-93.

47. Edwards JSA, Meiselman HL, Edward A, Lesher L. The influence of eating location on the acceptability of identical prepared food. Food Quality and Preference 2003; 14: 647-52.

\section{Susanne Bryngelsson}

SNF Swedish Nutrition Foundation

Ideon Science Park

SE-230 70

Lund

Sweden

Tel: +46 462862284

E-mail: susanne.bryngelsson@snf.ideon.se 